\title{
The Interdependence between the Demand of Fashion Industry and the Function of Fashion Education
}

\author{
Shiyuan Cheng \\ Department of Film \& Television Arts, Shanghai Publishing and Printing College, Shanghai, China \\ Email: 937542512@qq.com
}

How to cite this paper: Cheng, S.Y. (2018) The Interdependence between the Demand of Fashion Industry and the Function of Fashion Education. American Journal of Industrial and Business Management, 8 , 1065-1072.

https://doi.org/10.4236/ajibm.2018.84073

Received: March 31, 2018

Accepted: April 27, 2018

Published: April 30, 2018

Copyright $\odot 2018$ by author and Scientific Research Publishing Inc. This work is licensed under the Creative Commons Attribution International License (CC BY 4.0).

http://creativecommons.org/licenses/by/4.0/

(c) (i) Open Access

\begin{abstract}
When the cultural industry is booming, fashion industry and fashion education emerge as the times require, and they are also derived from each other. Through the research, it is found that their relationship is specific, and the fashion education extends from the traditional only to the education of the industry, the education of the market and the education of the consumers. The form of fashion education is still education, but the essence has evolved into the pursuit of fashion innovation and the indoctrination of fashion culture, which is required by the development of fashion industry. This pursuit and instillation is through the production, management, marketing, brand, design and propaganda of the fashion industry. The external performance of fashion education is to cultivate all kinds of professional talents in fashion industry, but it is rooted in the innovation and creative breakthrough of fashion industry and products, thus promoting the continuous development of fashion industry through the role of human resources in fashion industry, and finally reaching the goal of leading the fashion industry with the power of knowledge. Fashion industry is developing. Fashion education is also developing, and is more and more popular in front of fashion industry, leading the development of fashion industry.
\end{abstract}

\section{Keywords}

Fashion Education, Fashion Industry, Interdependence

\section{Introduction}

Under urbanization nowadays, the interdependence between the demand of fashion industry and the function of fashion education expresses an effect of agglomeration and superiority. 
The article is organized as follows. The first part mainly explains the formation of the concept of fashion industry and fashion education in the process of urbanization. The second part discusses the relationship between the demand of the fashion industry and the function of fashion education, such as the core function, supporting function, supporting function and derivative function, as well as the characteristics of the agglomeration effect and preemptive advantage at the moment of the increasingly urbanization process. The third part analyses the function of fashion education to promote the development of fashion industry and the mutual promotion and interaction between the two parties, and present the joint force state between the outside and the inside.

\section{The Demand of Fashion Industry Derivate from the Function of Its Own}

As a typical manifestation of the industry in international metropolis, fashion industry serves not as an individual industrial department, but as an industrial chain which is formed by the integration, elevation and combination of various traditional industrial resources. Therefore it possesses the integrative properties of the secondary and tertiary industry and is of great importance in the range of producer services. In industrial form, fashion industry represents a multi-industrial cluster portfolio which bridges the boundary between high-value-added advanced manufacturing industry and modern service industry; In product presentation, fashion industry is equivalent to the consumption services of medium and high-grade products which represents the prevalent aesthetic and consuming conception, as well to the products itself; In resource system, fashion industry is formed by six elements: landmark, celebrity, brand, platform, activity and culture [1]; in industrial feature, fashion industry gather several characteristics together: relevance, marginality, containing, diversification, leading, inclusion, creativity, superior thinking and variability.

The development of fashion industry also includes three basic steps: the cultivation of fashion creativity, the form of fashion contribution and last, the widespread of fashion influence. Besides, the main feature of fashion industrial development is its coalescence of elite and mass culture, which means it not only functions as the leader towards high-end and individuation by elite theory on design, but also responses for the awakening of mass's devotion and pursuit for fashionable lifestyle.

\subsection{Fashion Creativity}

Creativity is the fundamental of the fashion industry's development. It shows as the specific ability of design on narrow sense. Meanwhile in a broad sense, it reflects not only the creativity of every relevant departments, but also the ability of mixing different elements into the realm of fashion. Considering this, everything, basically, has the potential of being utilized to create new fashion, or even being fashion itself. These elements would influence the form of new fashion, 
vice versa, thus forming a dynamic network.

Generally speaking, fashion creativity roots in organized design, as well as in every part of society. Therefore it should be integrated from all sides for a far-reaching development of fashion industry, during which process fashion education weighs plays as a leading role.

\subsection{Fashion Contribution}

The significance of fashion contribution could be demonstrated in two sides: the contribution towards local economy, and towards global fashion industry. Fashion creativity fostering, the process of value realization starts to take form.

Fashion's contribution to local economy and global industry is mainly showed in the following aspects:

1) Constant promotion of fashion industrial added value and of the proportion of fashion industry in total economic amount.

2) Increasing number and quality of relevant occupation

3) Improving level of professionalization

4) Improving level of centralization

5) The integrity and maturity of fashion educational industry

\subsection{Fashion Influence}

Not only the fashion industry itself, but also the whole city would enhance its influence to global industry as the continuous development of fashion creativity and contribution. Talking about fashion influence, one should realize that a whole city's fashion influence is synchronized to its economic development. With the rapid development of Chinese economy, Shanghai, as one of the magnates, has widely spread its influence all over the world. According to a survey from Global Language Monitor (GLM, Texas, U.S.), Shanghai ranks highly in top-level fashion cities worldwide (No. 14 in 2007, No. 13 in 2008, No. 15 in 2009) and the third in all listed Asian cities, which is the only one in mainland China, thanks to the rapid development of economy and increasing international popularity [2]. However, on one side, the development of its fashion industry seems like a drag to this honor of top-level fashionable metropolis. On the other side, this invisible honor is in favor of the integration and development of Shanghai fashion industry. Its fashion industry being fully developed, Shanghai would become a true international fashionable city, thus ranking higher worldwide.

Fashion influence is mainly showed as follow:

1) The appealing to talents, enterprises and capital, from inland and abroad.

2) The attraction of global attention by fashion events, the ability of being spotlighted.

3) The attendance of top designers, brands and enterprise in fashion events.

4) Impression on outside.

5) The emergence of distinctive new industries. 
6) Fashion education has its influence throughout the world.

\section{The Function of Fashion Education Derivate from Its Demand for Individuation}

Currently, fashion education emerges as the vigorous development of global culture industry, especially in fashion industry. As a typical manifestation pattern of industries in international metropolis, fashion industry serves not as an individual department, but as a unique industrial chain which is integrated, promoted and combined by variety of traditional industrial resources. Therefore fashion education takes the responsibility of providing intellectual and professional support by developing talents of multilevel and offering technique appealing to the market's requirements of creativity, leadership and foresightedness, from different aspects such as fashion consciousness, elements, development and counsel. Furthermore, it also plays an important role in the construction of a stage where latest research and information are widely spread. The cultivation of creativity and imagination-very first level of fashion industrial development-is the most important and basic section in the development of fashion industry, and only could arise under the instruction of fashion education.

\subsection{Recognize the Function of Fashion Education}

While traditional education emphasizes passing on knowledge that already existing, fashion education improves based on the tradition. However, this newly-emerged form of education does not deviate far from the basic function of education. Rather, it focuses on knowledge factors, function of originality, and awareness of creativity in every pores of fashion industry. Because intrinsically fashion education has evolved as a pursuit for creativity and originality, through almost every parts of fashion industry including manufacture, management, marketing, brand, design and advertisement. As creativity and originality become the core of fashion education, different forms of education gradually emerged. All in all, fashion education, although appears to be only the cultivation of talents of various fields, has in fact deeply rooted in fashion industry and been functioning as the breakthrough in creativity and originality, thus promoting development and reaching the final goal of letting knowledge lead the direction in fashion industry [3].

Take Shanghai for example. As a rising star of international fashion exemplar, Shanghai's fashion industry has a promising future and also a rugged path ahead. The main reason lies in the deficiency of solid basis in fashion industry. However Shanghai would still catalyze the reaction on show in the field of fashion industry. It is because Shanghai, already equipped with profound experience of professional education, sufficient support of fashion industrial platform, perfect resources of talents, is capable of seizing the great chances of development inland and abroad, and then according to scientific development, launch the overall construction of the carrier of fashion education industry. 
Shanghai would definitely develop as an example of fashion education through international connection with developed region, and through the process which sets personnel training as core mission, increasing promotion of new brand and product marketing as basic theory, "Fashion Shanghai" as the theme and market-driven model as developing strategy

\subsection{Derive from the Function of Fashion Education}

As a huge conception, fashion education surely contains narrowly defined functions of education, and also enlarges education's area to the research of several other fields: fashion communication of marketing and society, fashion sustainment of knowledge and information, developing tendency of textile market, creativity and original design in textile, and industrialization of relevant researching achievement in education. Fashion education is stretched broadly to the education of industry, market and consumer.

The relevance of fashion education and fashion industry development: Since education has indirect correlation with social economy, fashion education, inherited the characteristic of traditional education, becomes an important part of fashion industrial chain by breaking through the traditional limitation and making tremendous profits, therefore gradually spread in to other fields. In this process, fashion education has successfully transformed into a brand new industry, at the time gained more promoting space for itself in fashion industry. The core reason lies in the direct connection between fashion industry and fashion education, during which process development of fashion industry is considered as the eternal aim of fashion education.

Fashion industry is powerfully reflected in high-end services, so is fashion education. Yet comparing to traditional service industry, service of fashion education obtains upper level of marketing service and higher development, also weighs much more on automatism, sustainment, creativity, the quality of service as well as the top-grade products.

\subsection{The Interdependence between the Demand of Fashion Industry and the Function of Fashion Education}

Fashion education has a tight connection with fashion industry: the boom of fashion industry brings about market's requirement for talents from various relevant fields. Fashion education, however, takes the responsibility of providing intellectual and professional support by developing talents of multilevel and offering technique appealing to the market's requirements of creativity, leadership and foresightedness, from different aspects such as fashion consciousness, elements, development and counsel. Furthermore, it also plays an important role in the construction of a stage where latest research and information are widely spread. Economic boom as well as the rise of fashion education industry drives the development of fashion industry, creating a fashion phenomenon which encourages the prosperity of whole market, thus creating a win-win situation (Figure 1). 


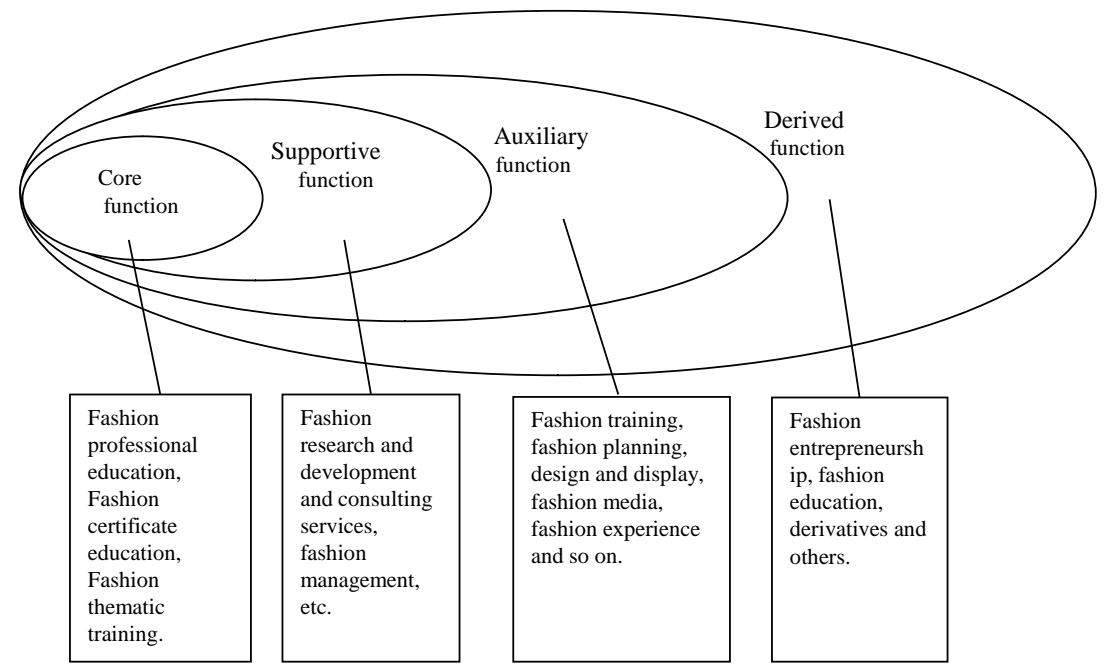

Figure 1. The classification of fashion education and the business classification of fashion industry.

1) Core function: fashion education and train

Facing the deficiency of talents, professional education and training, together with fashion seminar, should be widely held. The key of fashion industrial development is the competition of talents. What makes a talent is one's positive attitude, remarkable skills and wide range of knowledge [4]. Dynamic as it is, fashion industry requires more training and guidance for staff. Meanwhile larger enterprises are longing for more professional talents. And the expansion of fashion industry's influence would also arise people's interests in contributing themselves to it.

2) Supportive function: fashion $R \& D$ (Research and development) and counsel

Fashion research and development, counseling services and fashion management. Fashion R\&D is the soul of fashion industry, representing the competitive ability. And counsel works as an assistant in this process. The following aspects are of great significance in counseling supportive function: the ability of tracking latest fashion trend and development of textile manufacture home and abroad; Utilization of former ability as instruction and reference; Construction of information base of fashion; Survey on marketing and products; Invitation of experts in relevant fields; Offering advises on marketing, branding and products strategy. According to information base as well as the integrity of resources from outstanding colleges, fashion consulting would provide more assistance in prevailing art, fashion creativity, branding and flexibility of strategy.

3) Auxiliary function: fashion internship and display

Process which includes fashion internship, plan, design and display, etc. Fashion internship provides students with opportunities of participation and interaction with experts, thus learning through practice. In a short time students would make great progress in professional skills, practice experience and theory, 
approaching to the final goals of becoming an expert in fashion industry. This training-guidance model is also widely accepted as classical methods in French advanced fashion industry, and managed to cultivate thousands of talents with great practicing experience. POLIMODA, a fashion college in Italy, is famous for its efficient training in very short time thanks to its huge educational resources and good reputation.

4) Derived function: fashion entrepreneurship and media

This section contains fashion entrepreneurship, fashion media, fashion experience and so on. With the cultivation of fashion education, a great number of talents are itching of starting their own enterprise and career. Fashion education should make excessive use of their zeal by providing them with best fashion phenomenon, opportunities as well as original ideas and creative elements. Since the number of consumers with good taste and high requirement is increasing due to the rapid development of Shanghai as well as whole China, better fashion experience is eagerly required by the booming market of fashion industry. Meanwhile, the development of fashion media usually has positive correlation with the whole developing level of fashion industry. Therefore Shanghai should lay great importance on fashion media in order to prove its leadership in China's fashion field by expanding the influence of not only traditional but also newly-emerged media [5]. Shanghai's necessity of being international and professional in fashion industry also meet the need of its characteristic-to draw people's attention and interest to the greatest extension.

\section{Conclusion}

All in all, the interdependence between the demand of fashion industry and the function of fashion education is of great significance for current economic growth due to the tight interaction between those two. The function of fashion education has strong impulse on the development of fashion industry. According to the history of fashion, fashion's ability of creativity is the soul of its own development. And fashion education therefore cultivates talents who have creativity and originality, as well as other resources which are widely spread according to the industrial chain of fashion development. The counselling function of fashion education together with others paves the further way of fashion industrial development by providing then with professional strategy and research plan, thus promoting the efficacy of fashion counsel. That is the reason why the pioneers who devote themselves in the exploit of domesticated fashion market gain assistance and then make breakthrough mainly by the combination of fashion industry and education. All these functions are well equipped, and the key of industrial development lies basically in the abilities of precisely seizing the opportunities, predicting the trend of fashion. During the developing process of fashion industry, the overall functions of fashion education provide huge support for the industry, and gradually magnify the penetration of fashion education in every aspect of market and society. Therefore, its derived functions 
would expand the influence of fashion industry's needs and educational function, building a harmoniously self-feeding cycle of fashion, industry and education.

\section{References}

[1] Li, W.W. (2006) Introduction of Creative Industry. Xuelin Press, Shanghai.

[2] Gu, Q.L. (2002-2003) Cluster of China's Textile and Clothing Industry and Its competition. Development Report of China's Textile Industry.

[3] Wang, S.Z. (2008) Fashion Era. China Travel and Tourism Press, Beijing.

[4] Hawkins, J. (2006) Creativity Economy. Shanghai Joint Publishing Press, Shanghai.

[5] He, C.S. (2007) Creativity, from Knowledge to Capital-Shanghai's Thinking in Cultural Creative Industry. Shanghai Culture Press, Shanghai. 